\title{
The EORTC Ophthalmic Oncology Quality of Life Questionnaire Module (EORTC QLQ-OPT30). Development and Pre-Testing (Phase I-III)
}

Y Brandberg', B Damato², T Kivelä3 ${ }^{3}$ E Kock ${ }^{4}$ and $S$ Seregard ${ }^{4}$ for the EORTC Ophthalmic Oncology Task Force and the EORTC Quality of Life Group

\begin{abstract}
Aims The research objective was to develop a questionnaire module to be used, in addition to the European Organisation into Research and Treatment of Cancer (EORTC) QLQ-C30, for measurement of quality of life (QL) among patients with uveal melanoma treated with methods such as transpupillary thermotherapy, plaque radiotherapy, proton beam radiotherapy, local resection, and enucleation. The present paper describes the development through Phases I-III.

Methods Relevant QL issues were generated from literature search and from interviews with ophthalmologists, nurses, and patients with uveal melanoma representing three major treatment options: enucleation, plaque brachytherapy, and proton beam therapy. Results The provisional module was pretested in 61 patients from Finland, Sweden, and UK. The EORTC QLQ-OPT30 module consists of 26 items for all patients, and four additional items for patients receiving treatments other than enucleation. It measures ocular irritation, vision impairment, headache, worry about recurrent disease, problems with driving, problems with appearance functional problems due to vision impairment, and problems reading.

Conclusions Several treatment modalities are available for uveal melanoma. There is limited knowledge of the impact of these treatments on QL in the long and short term. We hope that the OPT30 module together with the EORTC QLQ-C30 core questionnaire can be a useful tool in research.
\end{abstract}

Eye (2004) 18, 283-289. doi:10.1038/

sj.eye. 6700639

Keywords: quality of life questionnaire; ocular melanoma; EORTC

\section{Introduction}

Uveal melanoma, with an annual incidence of six to eight per one million population, ${ }^{1-3}$ is the most common eye cancer with several thousand new patients each year worldwide. In addition to enucleation, a spectrum of eye conserving treatment options is now available, and the treatment for a particular patient is chosen depending on the size, location, and other characteristics of the tumour, the level of retained vision, and physician and patient preferences. ${ }^{4}$ Knowledge on effects of different treatments on quality of life (QL) could assist, in cases where there is an option, in the choice of the most appropriate treatment for individual patients.

Published data about the QL effects of uveal melanoma and its treatment are limited. ${ }^{5}$ In a prospective Swedish study, patients treated with enucleation and ruthenium plaque radiotherapy differed with respect to problems 1 year after treatment. ${ }^{5}$ There were no differences in generic QL (EORTC QLQ-C30), anxiety and depressive symptoms (Hospital Anxiety and Depression Scale), or posttraumatic distress (Impact of Event Scale). Lower values have been found for vitality and mental health among enucleated patients as
${ }^{1}$ Department of OncologyPathology

Karolinska Institutet Stockholm, Sweden

${ }^{2}$ Ocular Oncology Service St Paul's Eye Unit Royal Liverpool University Hospital Liverpool, UK

${ }^{3}$ Ocular Oncology and Vitreoretinal Service Department of Ophthalmology Helsinki University Central Hospital Helsinki, Finland

${ }^{4}$ Ophthalmic Pathology and Oncology Service St Eriks Eye Hospital Stockholm, Sweden

Correspondence:

Y Brandberg

Department of Oncology-

Pathology

Karolinska Institutet

Stockholm S-171 76

Sweden

Tel: + 46851772422

Fax: + 468326113

E-mail: yvonne.brandberg@ onkpat.ki.se

Received: 15 January 2003 Accepted: 6 May 2003 
compared to patients treated with radiation therapy, but there were no differences between the two groups on the Visual Function Questionnaire. ${ }^{6}$ The initiative to develop a questionnaire specific for intraocular cancer derived from the European Organisation for Research and Treatment of Cancer (EORTC) Ophthalmic Oncology Task Force (OOTF). They were interested in a questionnaire that could be used in international trials. Although standardised questionnaires were available for evaluating QL in ophthalmic patients, patients with cancer face additional problems, such as worry about recurrence of the disease. Furthermore, the treatment is in many cases associated with side effects. Thus, there was a need for a QL questionnaire especially for this patient group.

The EORTC QLQ-C30 is a core questionnaire assessing generic aspects of QL relevant for a broad range of cancer patients. ${ }^{7}$ It is a copyrighted instrument, which has been translated and validated into 43 languages and is used in several thousand studies worldwide. The QLQ-C30 consists of 30 items, comprising five functional scales, eight symptom scales and single items, and a scale on global health status. The items are scored on a four-point scale. Scales are computed according to the scoring manual. ${ }^{8}$ According to the approach, adopted by the EORTC Quality of Life Group (QLG), the core questionnaire is intended to be supplemented by more specific modules, covering disease- and treatmentrelated aspects. ${ }^{9,10}$ These modules are developed through four phases according to guidelines established by the QLG. ${ }^{9-11}$ Modules related to cancer in the breast (BR23), ${ }^{12}$ head and neck (H\&N35), ${ }^{13,14}$ and lung (LC13) ${ }^{15}$ have so far been validated in large-scale international field studies. ${ }^{8}$ A number of modules are under development in Phases III and IV (oesophageal, ovarian, bladder, brain, colorectal, gastric, pancreatic and prostate cancer, multiple myeloma, and satisfaction with care).

The research objective was to develop a module to be used, in addition to the EORTC QLQ-C30, for measurement of QL among patients with uveal melanoma treated with methods such as transpupillary thermotherapy, plaque radiotherapy, proton beam radiotherapy, local resection, and enucleation. The module was designed to be used before, during and after treatment. The present paper describes the development through Phases I-III.

\section{Material and methods}

Investigators in three tertiary referral centres for patients with eye cancer participated in this multicentre study. The Ocular Oncology Service of St Erik's Eye Hospital, Stockholm, and of Helsinki University Central Hospital, Helsinki, manage about $95 \%$ of patients with uveal melanoma in Sweden and Finland, respectively. The Ocular Oncology Service of St Paul's Eye Unit, Royal Liverpool University Hospital, Liverpool, manages about $33 \%$ of patients with uveal melanoma in the UK.

\section{Phases I and II: identification of relevant module items and operationalisation of issues into a provisional questionnaire}

Literature searches were performed regularly between 1994 and 1999, primarily by using MEDLINE and CANCERLIT. The relevant articles found were reviewed for additional references. All papers reporting on QL among patients with ocular tumours and those describing questionnaires measuring vision impairment and vision-related QL were reviewed. 'Driving status', 'reading ability', and 'vision-related problems' are examples of areas specific for patients with ocular melanoma. ${ }^{16-18}$ Studies on patients treated for other eye diseases were not considered further, because having a cancer diagnosis was considered a special case with respect to QL.

Issues chosen for the provisional questionnaire were obtained by interviews with patients, five ophthalmologists (three from Sweden, one from Finland, and one from UK), two nurses working with patients with uveal melanoma (one from Sweden and one from UK), and a psychologist with experience in interviewing patients with uveal melanoma in a QL study. Interviews with patients took place at St Eriks Eye Hospital and at the Department of Oncology-Pathology, Karolinska Institutet, Stockholm, Sweden. The interviewer was a psychologist (YB). Notes were taken during the interview, which took about $1 \mathrm{~h}$, and they were checked with the patient at the end of the session to avoid misunderstandings and to make corrections. The interviews were carried out according to the EORTC Guidelines for Module Development., ${ }^{9,10}$

The provisional list of issues was prepared in collaboration between Dr Damato in Liverpool and Dr Kock, Dr Seregard, and Dr Brandberg in Stockholm. The list was then reviewed by one ophthalmologist in Stockholm (Dr Landau) and by Dr Kivelä in Helsinki. The criteria described for modules and their constituent elements ${ }^{9}$ were applied for operationalisation of items. The provisional module (OPT37) consisted of 37 items.

\section{Phase III: pretesting of the OPT37 provisional module}

Phase III was designed to identify problems with specific items and to ensure that the module covered items relevant to the target patient population.

Patients from the three participating centres were enrolled so that three main treatment options were 
primarily represented: enucleation, plaque brachytherapy, and proton beam therapy. The EORTC QLG guidelines demanded 10-15 patients per subgroup. The patients completed the EORTC QLQ-C30, the OPT37 provisional module and a structured debriefing interview at a regular follow-up appointment in the presence of a research nurse or a physician. In Finland, an ophthalmologist administered the questionnaires and performed the debriefing interview, whereas in Sweden and UK, nurses were responsible for data collection. The debriefing interviews were carried out according to the EORTC QLG Guidelines for Module Development. ${ }^{10}$

\section{Statistical analysis}

The results were summarised according to response prevalence (range of scores and mean score). These data were calculated for the entire series and for the three main subgroups. Items with mean score $<1.5$ in the entire series and in two of the three subgroups were considered for exclusion. ${ }^{19}$ Items fulfilling these exclusion criteria, but having a range of three in the entire series and in at least one of the subgroups were retained. Results from the debriefing interview were also taken into account when deciding on exclusion of items.

\section{Results}

Phases I and II: identification of relevant module items and operationalisation of issues into a provisional questionnaire

The literature search by 15 October 1999, revealed nine papers under the following headings: 'Ocular melanoma and QL' (six hits), 'Choroidal melanoma and QL' (five hits), 'Ocular melanoma and psychology' (four hits), 'Choroidal melanoma and psychology' (four hits), and 'Ocular melanoma and anxiety' (one hit). A total of 23 papers were identified by further review and literature search. No published questionnaire for the measurement of QL and disease- and treatment-specific problems for patients with uveal melanoma were found at that time. Six measures of eye-related diseases were identified. They were considered in order to identify domains for the provisional questionnaire, but none of their items were eventually included.

Eight patients were interviewed (five women and three men). The mean age was 58 years (range, 39-75 years). Six were treated with ruthenium plaque brachytherapy and two with enucleation.

A list of 37 items in eight domains was constructed based on staff and patient comments (Table 1). Certain domains cover both symptoms of the disease as well as effects of treatment (eg uveal melanoma may impair vision, and after treatment with brachytherapy vision may become even worse).

The questionnaire format was intended to be compatible with the EORTC QLQ-C30 core questionnaire with four response alternatives ranging from 'Not at all' to 'Very much' (Table 1). The same time frame 'During the past week' was also used. The intention was not to exclude any relevant issue. The EORTC QLG Item bank was used to search for overlapping items in other questionnaires.

The issues were organized with the intention to start with symptoms, followed by vision impairment. Problems in reading and driving are functional problems associated with vision impairment. Problems in concentrating and judging distances may have an impact on these functions. For many patients, loss of reading vision and the ability to drive a car have great impact on QL. These were therefore included as separate domains. The items about worry for death and recurrence were included in the middle of the questionnaire. These items were supposed to be the ones most likely to evoke anxiety, and were therefore placed before concluding items assessing functional aspects, which were considered to be less emotional.

The provisional module, EORTC QLQ-OPT37, was developed in English and translated into Finnish, Swedish, and German. Two members of the EORTC QLG, Dr Kristin Bjordal and Dr Jane Blazeby reviewed the questionnaire in 1998.

\section{Phase III: pretesting of the provisional module}

A total of 61 patients participated in the pretesting, nine from Finland, 18 from Sweden, and 34 from UK (29 women $(48 \%)$ and 32 men, mean age 62 years; range 29-83 years) (Table 2). The patients underwent eight different treatments, including observation.

The domains and items, the percentage of patients responding, the mean scores and the range of scores are shown for the entire series and for patients treated with enucleation, plaque brachytherapy, and proton beam treatment (Table 1). The three main treatment subgroups comprised from 11 to 28 patients each.

Six items were deleted $(34,44,53,56,59$, and 62). The reasons for deleting items 34,53 , and 56 were mean score $<1.5$, indicating that these items had limited relevance for this group of patients, and a range of two both in the entire sample and in all three subgroups, indicative of low variation. Some patients reported problems in understanding item 44 ('Did you see things that you knew were not there?'). The mean scores were $\leq 1.5$ and the response rate was 95\%. Items 59 and 62 had mean scores $<1.5$ both in the entire series and in all three subgroups. 
Table 1 OPT-37:domains, items, percentage of all patients responding, and mean scores and range of scores for the entire sample and for patients treated with ruthenium plaque radiotherapy, enucleation, and beam treatment

\begin{tabular}{|c|c|c|c|c|c|c|c|c|c|c|}
\hline \multirow[t]{2}{*}{ Domains } & \multirow[t]{2}{*}{ Items } & \multicolumn{3}{|c|}{ Total sample $\mathrm{n}=61$} & \multicolumn{2}{|c|}{$\begin{array}{c}\text { Radioactive } \\
\text { plaque } \\
\text { brachytherapy, } \\
\mathrm{n}=28\end{array}$} & \multicolumn{2}{|c|}{$\begin{array}{c}\text { Enucleation, } \\
\mathrm{n}=12\end{array}$} & \multicolumn{2}{|c|}{$\begin{array}{c}\text { Proton beam, } \\
\mathrm{n}=11\end{array}$} \\
\hline & & $\begin{array}{l}\text { Percentage } \\
\text { Responding }\end{array}$ & Mean & Range & Mean & Range & Mean & Range & Mean & Range \\
\hline \multirow{8}{*}{$\begin{array}{l}\text { Ocular } \\
\text { irritation } \\
\text { (symptoms) }\end{array}$} & $\begin{array}{l}\text { 31. Did you have any grittiness of the } \\
\text { treated eye or had a foreign body sensation? }\end{array}$ & 100 & 1.67 & 3 & 1.86 & 3 & 1.33 & 1 & 1.36 & 1 \\
\hline & $\begin{array}{l}\text { 32. Did you feel any pain, soreness or } \\
\text { discomfort in or around the treated eye? }\end{array}$ & 98 & 1.57 & 3 & 1.74 & 3 & 1.33 & 2 & 1.27 & 1 \\
\hline & $\begin{array}{l}\text { 33. Did you have any itching in your treated } \\
\text { eye? }\end{array}$ & 97 & 1.46 & 2 & 1.56 & 2 & 1.58 & 2 & 1.30 & 1 \\
\hline & $\begin{array}{l}\text { 34. Did cold wind cause any pain in the treated } \\
\text { eye? }\end{array}$ & 98 & 1.38 & 2 & 1.48 & 2 & 1.42 & 2 & 1.09 & 1 \\
\hline & $\begin{array}{l}\text { 35. Did watering in the treated eye trouble } \\
\text { you? }\end{array}$ & 98 & 1.71 & 3 & 1.59 & 2 & 2.08 & 2 & 1.64 & 2 \\
\hline & $\begin{array}{l}\text { 36. Were you troubled by any discharge } \\
\text { from your treated eye? }\end{array}$ & 100 & 1.34 & 2 & 1.21 & 1 & 2.00 & 2 & 1.09 & 3 \\
\hline & $\begin{array}{l}\text { 37. Did you suffer from dryness in your } \\
\text { treated eye? }\end{array}$ & 100 & 1.43 & 3 & 1.32 & 2 & 1.50 & 1 & 1.64 & 3 \\
\hline & $\begin{array}{l}\text { 38. Were you troubled by any defects in } \\
\text { your side vision? }\end{array}$ & 93 & 1.91 & 3 & 1.69 & 3 & 2.20 & 3 & 2.36 & 3 \\
\hline \multirow{8}{*}{$\begin{array}{l}\text { Vision } \\
\text { impairment } \\
\text { (symptoms }\end{array}$} & $\begin{array}{l}\text { 39. Were you troubled with double vision } \\
\text { when looking straight ahead? }\end{array}$ & 93 & 1.42 & 3 & 1.44 & 3 & 1.33 & 2 & 1.46 & 3 \\
\hline & $\begin{array}{l}\text { 40. Did you have trouble with double vision } \\
\text { when looking side-ways? }\end{array}$ & 95 & 1.29 & 3 & 1.29 & 3 & 1.33 & 1 & 1.27 & 2 \\
\hline & $\begin{array}{l}\text { 41. Did things appear distorted out of your } \\
\text { treated eye? }\end{array}$ & 90 & 1.84 & 3 & 1.78 & 3 & 1.00 & 1 & 2.36 & 3 \\
\hline & $\begin{array}{l}\text { 42. Did you see flashes or balls of light with } \\
\text { your treated eye? }\end{array}$ & 90 & 1.54 & 3 & 1.71 & 3 & 1.00 & 1 & 1.30 & 1 \\
\hline & 43. Did you see floaters with your treated eye? & 92 & 1.75 & 3 & 1.89 & 3 & 1.00 & 1 & 1.72 & 2 \\
\hline & $\begin{array}{l}\text { 44. Did you see things that you knew were not } \\
\text { there? }\end{array}$ & 95 & 1.28 & 3 & 1.39 & 3 & 1.00 & 1 & 1.45 & 2 \\
\hline & $\begin{array}{l}45 . \text { Did the vision of the treated eye interfere } \\
\text { with the other eye? }\end{array}$ & 89 & 1.48 & 3 & 1.43 & 3 & 2.00 & 2 & 1.45 & 3 \\
\hline & $\begin{array}{l}\text { 46. Did your eye feel uncomfortable in } \\
\text { bright light? }\end{array}$ & 93 & 1.86 & 3 & 2.04 & 3 & 1.00 & 1 & 2.09 & 3 \\
\hline Headache & Did you have headaches? & 100 & 1.51 & 3 & 1.57 & 3 & 1.42 & 3 & 1.64 & 3 \\
\hline \multirow{6}{*}{$\begin{array}{l}\text { Worry about } \\
\text { recurrent } \\
\text { disease }\end{array}$} & $\begin{array}{l}\text { 48. Were you worried about your health in } \\
\text { the future? }\end{array}$ & 100 & 2.10 & 3 & 2.00 & 3 & 2.42 & 3 & 1.81 & 3 \\
\hline & $\begin{array}{l}\text { 49. Were you worried about tummour } \\
\text { recurring in the treated eye? }\end{array}$ & 95 & 2.10 & 3 & 2.19 & 3 & 1.80 & 3 & 1.73 & 2 \\
\hline & $\begin{array}{l}50 . \text { Were you worried about tumour } \\
\text { recurring in other parts of the body? }\end{array}$ & 98 & 2.25 & 3 & 2.30 & 3 & 2.33 & 3 & 1.73 & 2 \\
\hline & $\begin{array}{l}\text { 51. Were you worried about dying because of the } \\
\text { tumour? }\end{array}$ & 98 & 1.75 & 3 & 1.67 & 3 & 1.58 & 2 & 1.46 & 3 \\
\hline & 52. Were you worried about losing the eye? & 85 & 2.40 & 3 & 2.44 & 3 & 2.75 & 3 & 2.0 & 3 \\
\hline & 53. Did you have regrets trying to save the eye? & 89 & 1.07 & 1 & 1.07 & 1 & 1.20 & 1 & 1.10 & 3 \\
\hline \multirow[t]{2}{*}{$\begin{array}{l}\text { Problems } \\
\text { with driving }\end{array}$} & $\begin{array}{l}54 . \text { Did you have difficulty driving in } \\
\text { daylight because of your vision? }\end{array}$ & 85 & 1.36 & 3 & 1.33 & 3 & 1.71 & 3 & 1.00 & 0 \\
\hline & $\begin{array}{l}55 . \text { Did you have difficulty driving in dark } \\
\text { because of your vision? }\end{array}$ & 85 & 1.92 & 3 & 2.07 & 3 & 2.29 & 3 & 1.67 & 3 \\
\hline \multirow{3}{*}{$\begin{array}{l}\text { Problems } \\
\text { with } \\
\text { appearance }\end{array}$} & 56. Did you have trouble going out in public? & 100 & 1.33 & 2 & 1.29 & 2 & 1.58 & 2 & 1.09 & 1 \\
\hline & 57. Did your appearance bother you? & 100 & 1.16 & 3 & 1.11 & 1 & 1.58 & 3 & 1.00 & 0 \\
\hline & $\begin{array}{l}58 \text {. Were you dissatisfied with the cosmetic } \\
\text { result after surgery? }\end{array}$ & 95 & 1.41 & 3 & 1.59 & 3 & 1.42 & 3 & 1.30 & 3 \\
\hline
\end{tabular}


Table 1 (continued)

\begin{tabular}{|c|c|c|c|c|c|c|c|c|c|c|}
\hline \multirow[t]{2}{*}{ Domains } & \multirow[t]{2}{*}{ Items } & \multicolumn{3}{|c|}{ Total sample $\mathrm{n}=61$} & \multicolumn{2}{|c|}{$\begin{array}{c}\text { Radioactive } \\
\text { plaque } \\
\text { brachytherapy, } \\
\mathrm{n}=28\end{array}$} & \multicolumn{2}{|c|}{$\begin{array}{c}\text { Enucleation, } \\
\mathrm{n}=12\end{array}$} & \multicolumn{2}{|c|}{$\begin{array}{c}\begin{array}{c}\text { Proton beam, } \\
\mathrm{n}=11\end{array}\end{array}$} \\
\hline & & $\begin{array}{l}\text { Percentage } \\
\text { Responding }\end{array}$ & Mean & Range & Mean & Range & Mean & Range & Mean & Range \\
\hline \multirow{8}{*}{$\begin{array}{l}\text { Functional } \\
\text { problems } \\
\text { due to vision } \\
\text { impairment }\end{array}$} & $\begin{array}{l}\text { 59. Did you have difficulty seeing well enough } \\
\text { to watch television? }\end{array}$ & 100 & 1.36 & 3 & 1.49 & 3 & 1.17 & 1 & 1.09 & 1 \\
\hline & $\begin{array}{l}\text { 60. Did you have difficulty pouring (e.g., tea } \\
\text { or coffee)? }\end{array}$ & 100 & 1.49 & 3 & 1.39 & 3 & 2.08 & 3 & 1.18 & 1 \\
\hline & $\begin{array}{l}\text { 61. Did you have difficulty seeing to walk in } \\
\text { crowded areas? }\end{array}$ & 100 & 1.49 & 3 & 1.43 & 3 & 1.82 & 3 & 1.27 & 1 \\
\hline & $\begin{array}{l}\text { 62. Did you have difficulty seeing to walk in the } \\
\text { street? }\end{array}$ & 97 & 1.41 & 3 & 1.39 & 3 & 1.46 & 2 & 1.40 & 1 \\
\hline & $\begin{array}{l}\text { 63. Did you have any difficulty with steps or } \\
\text { pavements? }\end{array}$ & 98 & 1.60 & 3 & 1.54 & 3 & 1.91 & 2 & 1.46 & 1 \\
\hline & $\begin{array}{l}\text { 64. Did you have any difficulty walking } \\
\text { downwards in stairs or on uneven ground? }\end{array}$ & 100 & 1.67 & 3 & 1.61 & 3 & 1.83 & 2 & 1.73 & 2 \\
\hline & $\begin{array}{l}\text { 65. Did you have difficulty judging } \\
\text { distances? }\end{array}$ & 100 & 1.69 & 3 & 1.68 & 3 & 2.17 & 3 & 1.27 & 1 \\
\hline & $\begin{array}{l}\text { 66. Were your activities limited in any way } \\
\text { because of your vision? }\end{array}$ & 100 & 1.62 & 3 & 1.54 & 3 & 1.75 & 3 & 1.46 & 3 \\
\hline $\begin{array}{l}\text { Problems } \\
\text { with reading }\end{array}$ & $\begin{array}{l}\text { 67. Did you have difficulty with reading } \\
\text { because of your vision }\end{array}$ & 100 & 1.74 & 3 & 1.79 & 3 & 1.50 & 2 & 1.73 & 3 \\
\hline
\end{tabular}

Items in italics are deleted in the final version (opt-37).

Table 2 Details of 61 patients interviewed during Phase III pretesting

\begin{tabular}{lr}
\hline Country, no of patients (\%) & \\
Finland & $9(15)$ \\
Sweden & $18(29)$ \\
UK & $34(56)$ \\
Gender, no of patients (\%) & \\
Female & $29(48)$ \\
Male & $32(52)$ \\
& \\
Mean age, years (range) & \\
Women & $61.4(34-80)$ \\
Men & $62.0(29-83)$ \\
Total & $61.7(29-83)$ \\
& \\
Treatments, no of patients (\%) & \\
Enucleation & $12(20)$ \\
Radioactive plaque brachytherapy & $28(46)$ \\
Ruthenium-106 & $22(36)$ \\
Iodine-125 & $6(10)$ \\
Proton beam irradiation & $11(18)$ \\
Other modalities & $10(16)$ \\
Transpupillary thermotherapy & $4(6.5)$ \\
Local resection & $4(6.5)$ \\
Endoresection & $1(1.5)$ \\
Observation & $1(1.5)$ \\
\hline &
\end{tabular}

Items 39, 40, and 45 (Table 1) were retained despite low mean scores. These items were deemed to be important QL issues for patients who undergo specific treatments.
Diplopia after (items 39 and 40) is a typical problem for those patients who undergo plaque radiotherapy. Therefore, it was suggested by the clinicians that these items be retained. Interference of the treated eye with the vision of the other eye (item 45) was a problem reported by enucleated patients. This item was thus included despite the low mean scores for the other subgroups and for the entire series.

The analysis of mean scores, response rates, and comments from patients participating in pretesting revealed four items on vision impairment not to be relevant for patients who had undergone enucleation $(41,42,43$, and 46). These items referred to 'the treated eye', and some enucleated patients found it difficult to respond. In addition, the mean score and range of scores among enucleated patients on these items was 1 . The domain 'Vision impairment' was therefore moved to the end of the questionnaire and a sentence 'Please, respond to these items only if applicable' was added. Thus, the final EORTC QLQ-OPT30 module consists of 30 items, 26 items for all patients and four additional items for patient receiving treatments other than enucleation. It measures ocular irritation, vision imparment, headache, worry about recurrent disease, problems with driving, problems with appearance, functional problems due to vision impairment, and problems reading.

The EORTC QLQ-OPT30 was reviewed by two members of the EORTC QLG, Dr Eva Greimel and 
Dr Anne Bredart, who made valuable comments. In addition, three ophthalmologists at the Institute Curie, Paris commented on the module. Item 51 concerning worry about dying as a result the tumour was omitted, despite high mean scores, because it was considered to be very upsetting in France. After this deletion, the EORTC QLQ-C30 consists of 30 items.

\section{Discussion}

A new module, the EORTC QLQ-OPT30, for assessing QL in patients with uveal melanoma was developed within the framework of the EORTC QLG. Like other EORTC QLQ modules, the EORTC QLQ-OPT30

questionnaire is designed to be used in conjunction with the core questionnaire, the EORTC QLQ-C30, and not as a standalone questionnaire. Since these treatments are also used for other intraocular tumours, the EORTC QLQ-OPT30 module may even have a wider application in the future.

Unlike other ophthalmic conditions, such as cataract and macular degeneration, the main objective of treating uveal melanoma is the eradication of all viable tumour cells, if possible conserving the eye with useful vision. Furthermore, unlike most other ocular procedures, treatment of uveal melanoma by laser, radiotherapy, and local resection are often associated with a wide range of unavoidable side effects, such as tear film instability and neovascular glaucoma, which can be quite distressing to the patient. In addition, the cancer diagnosis and prospects of losing vision and the eye causes psychological distress for many patients. For these reasons, it is especially important to measure patientcentred outcomes when assessing the treatment of uveal melanoma.

The questionnaire was developed according to EORTC QLG Guidelines for Module Development, ${ }^{10}$ which would ensure that the questionnaire includes the symptoms and concerns that patients with uveal melanoma consider the most important. Our interviews with patients also show that the questions were easily understood and of relevance. However, the final testing of the questionnaire has still to be undertaken. The next step in the development of the EORTC QLQ-OPT30 will be a larger international Phase IV field study, in which the questionnaire is tested with respect to reliability, validity, and crosscultural applicability. ${ }^{10}$

The translations from English to Finnish and Swedish were administered by the EORTC QL Unit according to the guidelines for translation of questionnaires. ${ }^{20}$ This procedure is very thorough, including forwardbackward translations, which aims to ensure that the meanings of the items are consistent.
Most patients considered the items to be relevant and few had suggestions for additional items. Two patients suggested, however, that items concerning information at diagnosis and communication with the doctor in charge should be added. The EORTC QLQ-OPT30 module is intended to include only items specific for patients with uveal tumours, and these other areas are better covered in the module on patient satisfaction, which is under development by the EORTC QLG. We therefore decided not to expand the module with such items. In addition, as the number of items in the provisional OPT37 module exceeded the recommended maximum of 30 in the Guidelines for Module Development, ${ }^{10}$ one major goal of the pretesting was to reduce rather than increase the number of items.

The item concerning worry about dying as a result of the tumour was omitted after comments from three French ophthalmologists. They considered this item to be very upsetting in France. The present module was tested in three countries. There might be cultural differences, making a particular item impossible to ask. We consider the issue about worry about recurrence to be sufficiently covered by items $48-50$ and 52 .

Although a number of ophthalmic questionnaires have been developed, as far as we are aware, few especially address the concerns of patients with uveal melanoma. The psychometric properties of a questionnaire (MOOD, Measure of Outcome in Ocular Disease), including 21 items intended to measure QL were tested in patients who had been treated for ocular melanoma. ${ }^{18}$ This questionnaire was shown to be reliable, valid and acceptable to the patients. This questionnaire was validated by comparison with the subscales in the Medical Outcome Study Short Form (SF-36), an instrument for the assessment of general aspects of QL such as physical, social and role functioning. SF-36 has also been used in a study of QL in patients with choroidal melanoma, showing a similar SF-36 profile with slightly higher QL among the patients as compared to normative data from the US population ${ }^{21}$ and higher Vitality and Mental Component subscales among patients treated with radiation therapy as compared to enucleation. ${ }^{5}$ Our questionnaire is designed to cover aspects of uveal melanoma that are not included in the generic questionnaires such as EORTC QLQ-C30 and SF36. It should be used together with the EORTC QLQ-C30 to detain a comprehensive picture of QL among patients with uveal melanoma undergoing various treatments.

Several treatment modalities are available for uveal melanoma. There is limited knowledge of the impact of these treatments on QL in the long and short term. The Phase III data suggest differences in QL and perceived symptoms between the various treatment modalities. We expect EORTC QLQ-OPT30 to be particularly valuable 
in comparing symptoms between three major treatment modalities. For example, with a particular subgroup of tumours, plaque radiotherapy, and proton beam radiotherapy, may be equally successful at conserving visual acuity and achieving local tumour control, but one treatment may be shown to cause greater discomfort. This questionnaire may help resolve the longstanding debate as to whether or not patients experience fewer problems if the eye is salvaged than after enucleation.

There is scope for further investigation of this matter, performed with sufficient patient numbers to allow comparisons of subgroups, categorized according to age, gender, and type of treatment. We hope that the OPT30 module, together with the EORTC QLQ-C30 core questionnaire, can be a useful tool in research worldwide.

\section{Acknowledgements}

The module development process, Phases I-III, has been supported by grants from the Swedish Cancer Society, the Cancer Society in Stockholm, the King Gustav V Jubilee Fund and The Swedish Association for Cancer and Trafic Victims. We thank the clinicians, nurses, and patients who participated in the module development process. We also thank the reviewers of Phase I-II report, Kristin Bjordal and Jane Blazeby, and the reviewers of the Phase III report, Eva Greimel and Anne Bredart.

\section{References}

1 Bergman L, Seregard S, Nilsson B, Ringborg U, Lundell G, Ragnarsson-Olding B. Incidence of uveal melanoma in Sweden from 1960 to 1998. Invest Ophthalmol Vis Sci 2002; 43: 2579-2583.

2 Egan KM, Seddon JM, Glynn RJ, Gragoudas ES, Albert DM. Epidemiologic aspects of uveal melanoma. Surv Ophthalmol 1988; 32: 239-251.

3 Scotto J, Fraumeni JF, Lee JAH. Melanomas of the eye and other non-cutaneous sites: epidemiological aspects. J Natl Cancer Inst 1976; 56: 489-491.

4 Damato BE. An approach to the management of patients with uveal melanoma. Eye 1993; 7: 388-397.

5 Brandberg Y, Kock E, af Trampe E, Seregard S. Psychological reactions and quality of life in patients with posterior uveal melanoma treated with ruthenium plaque therapy or enucleation. Eye 2000; 14: 839-846.

6 Cruickshanks KJ, Fryback DG, Nondahl DM, Robinson N, Keesey U, Dalton DS et al. Treatment choice and quality of life in patients with choroidal melanoma. Arch Ophthalmol 1999; 117: 461-467.

7 Aaronson NK, Ahmedzai S, Bergman B, Bullinger M, Cull A, Duez NJ et al. The European Organisation for Research and Treatment of Cancer QLQ-C30: A quality-of-life instruments for use in international clinical trials in oncology. J Natl Cancer Inst 1993; 85: 365-376.

8 Fayers PM, Aaronson NK, Bjordal K, Groenvold M, Curran D, Bottomley A on behalf of the EORTC Quality of Life Group. The EORTC QLQ-C30 Scoring Manual, 3rd Ed. EORTC: Brussels, 2001.

9 Sprangers MAG, Cull A, Groenvold M, Bjordal K, Blazeby J, Aaronson NK for the EORTC Quality of Life Study Group. The European Organization for Research and Treatment of Cancer approach to developing questionnaire modules: an update and overview. Qual Life Res 1998; 7: 291-300.

10 Sprangers MAG, Cull A, Groenvold M on behalf of the EORTC Quality of Life Study Group. EORTC Quality of Lilfe Study Group Guidelines for Developing Questionnaire Modules. EORTC: Brussels, 1998.

11 Sprangers MAG, Cull A, Bjordal K, Groenvold M, Aaronson NK for the EORTC Study Group on Quality of Life. The European Organization for Research and Treatment of Cancer approach to quality of life assessment: guidelines for development of questionnaire modules. Qual Life Res 1993; 2: $287-295$.

12 Sprangers MAG, Groenvold M, Arrarras JI, Franklin J, de Velde A, Muller M et al. The European Organization for Research and Treatment of Cancer breast cancer-specific quality-of-life questionnaire module: first results from a three-country field study. J Clin Oncol 1996; 14: 2756-2768.

13 Bjordal K, Ahlner-Elmqvist M, Tollesson E, Jensen AB, Razavi D, Maher EJ et al. Development of a European Organization for Research and Treatment of Cancer (EORTC) questionnaire module to be used in quality of life assessments in head and neck cancer patients. Acta Oncol 1994; 33: 879-885.

14 Bjordal K, de Graeff A, Fayers A, Hammerlid E, van Pottelsberghe, Curran D et al. A 12 country field study of the EORT QLQ-C30 (version 3) and the head and neck cancer specific module (The EORTC QLQ-H\&N35). Eur J Cancer 2000; 36: 213-219.

15 Bergman BB, Aaronson NK, Ahemdzai S, Kaasa S, Sullivan M. The EORTC QLQ-LC13: a modular supplement to the EORTC core quality of life questionnaire (QLQ-C30) for use in lung cancer clinical trials. Eur J Cancer 1994; 30A: 635-642.

16 Augsburger JJ, Goel SD. Visual function following enucleation or episcleral plague radiotherapy for posterior uveal melanoma. Arch Ophthalmol 1994; 112: 786-789.

17 Edwards MG, Schachat AP. Impact of enucleation for choroidal melanoma on the performance of visiondependent activities. Arch Ophthalmol 1991; 109: 519-521.

18 Foss AJE, Lamping DL, Schroter S, Hungerford J. Development and validation of a patient based measure of outcome in ocular melanoma. Br J Ophthalmol 2000; 84: 347-351.

19 Blazeby JM, Alderson D, Winstone K, Steyn R, Hammerlid E, Arraras J et al. Development of an EORTC Questionnaire Module to be used in quality of life assessment for patients with oesophageal cancer. Eur J Cancer 1996; 32A: 1912-1917.

20 Cull A, Sprangers M, Bjordal K, Aaronson N on behalf of the EORTC Quality of Life Study Group. EORTC Quality of Lilfe Study Group Translation Procedure EORTC, Brussels, 1998.

21 Melia BM, Moy CS, McCaffery L. Quality of life in patients with choroidal melanoma: a pilot study. Ophthalmol Epidemiol. 1999; 6: 19-28. 